Revista de Economia Política, vol. 38, $n^{\circ} 3$ (152), pp. 510-525, julbo-setembro/2018

\title{
A Virtù Econômico-Monetária
}

\author{
The Economic-Monetary Virtù
}

MAURICIO METRI*

RESUMO: Este artigo propõe uma análise sobre economia e moeda no campo das práticas geoestratégicas, ou seja, como parte da virtù das autoridades centrais que comandam as unidades político-territoriais do sistema internacional. Argumenta-se que as disputas geopolíticas implicam desafios, por um lado, associados ao desenvolvimento de forças produtivas e militares e, por outro, relacionados à capacidade de gasto e financiamento da autoridade central. Para tanto, este artigo parte da dimensão espaço enquanto categoria analítica, associada a uma visão realista sobre o funcionamento do sistema internacional, para assim empreender uma análise sobre os saberes econômico e monetário a partir de dinâmicas geopolíticas.

PALAVRAS-CHAVES: Geografia; Território; Geopolítica; Economia e Moeda.

ABSTRACT: This article proposes to think about economy and currency as geo-strategic practices; in other words, as part of the central authorities' virtù that command the political-territorial units. It is argued that geopolitical disputes imply challenges, on the one hand, associated with the development of productive and military forces and, on the other hand, related to the central authority's spending capacity. Thereunto, this article articulates a reflection on the spatial dimension as an analytical category and a realistic view of the international system, in order to undertake an analysis of economic and monetary knowledge from of geopolitical challenges.

KEYWORDS: Geography; Territory; Geopolitics; Economics and Currency.

JEL Classification: F50; F52; E42; N40.

\footnotetext{
* Professor de Economia Política Internacional, Instituto de Relações Internacionais e Defesa (IRID), Universidade Federal do Rio de Janeiro (UFRJ), RJ - Brasil. E-mail: metri.mauricio@gmail.com.
} 


\section{INTRODUÇÃO}

O espaço geográfico tem atuado como uma das estruturas que balizam a trajetória das civilizações ao longo do tempo. Seus aspectos físicos condicionam de diferentes formas os movimentos dos homens. Por outro lado, na medida em que as relações entre as unidades político-territoriais de um sistema se estruturam com base em uma perene pressão competitiva de uns em relação aos outros, o conhecimento desse espaço acaba por ganhar maior relevância no modo como cada unidade responde a tais ameaças. A partir daí se desenvolveu o conhecimento geográfico ${ }^{1}$, o qual se tornou um elemento comum e integrador de diferentes práticas estratégicas implementadas por essas unidades.

O objetivo deste trabalho é refletir de forma articulada, por meio da dimensão do espaço, sobre três práticas que fazem parte do exercício estratégico (parte da virtù) das autoridades centrais que comandam as unidades político-territoriais ante os desafios característicos do sistema internacional, a saber:

a) conhecimento geográfico é parte constitutiva da formulação de qualquer estratégia relativa às questões de segurança e defesa;

b) desenvolvimento de forças produtivas e militares e, também, o provimento de recursos materiais necessários ao esforço de preparação para possíveis disputas e conflitos, não ocorrem à revelia das especificidades do espaço ocupado e organizado para tais fins; e

c) a organização de um sistema tributário de pagamentos, estruturado com base em uma moeda (de conta), que viabilize tanto o desenvolvimento das atividades produtivas, quanto a extorsão de recursos materiais e humanos, assim como a alavancagem da capacidade de financiamento e gasto da autoridade central, não se desenvolve dissociado do espaço de dominação da autoridade central.

Para tanto, do ponto de vista metodológico, este artigo empreende uma reflexão sobre a dimensão espacial (geográfica e territorial) enquanto categoria analítica, associada a uma visão realista sobre a forma de funcionamento do sistema internacional. Com base nessa análise, realiza-se uma interpretação sobre os saberes econômico e monetário à luz da geopolítica, pensando-os no campo do que é (geo)estratégico.

Além de uma conclusão ao final, o presente artigo está estruturado com base em outras três seções. Na próxima, analisam-se tanto a centralidade do espaço concreto à vida humana quanto a natureza política dos territórios em geral. Em seguida, a partir de uma perspectiva realista, discutem-se as dimensões geopolítica e geoeconômica do sistema internacional. Por fim, apresenta-se uma interpretação não convencional sobre assuntos monetários a partir de um ponto de vista (geo) estratégico.

${ }^{1}$ Ver Lacoste (1985). 


\section{DO IMPERATIVO ESPACIAL AO IMPERATIVO TERRITORIAL}

Em seu artigo "História e Ciências Sociais: a Longa Duração" publicado na Revista dos Annales em 19582, o historiador Fernand Braudel cunhou o termo coerção geográfica ao pensar nas estruturas que balizam os movimentos dos homens ao longo do tempo, atuando sobre estes como "prisões de longa duração" (Braudel, 1969: 50). Não por outra razão, incorporou o espaço físico como ponto de partida em algumas de suas mais importantes obras ${ }^{3}$, mais precisamente no que se refere às relações do homem com o ambiente externo, a fim de revelar uma das realidades que constrangem os caminhos das sociedades.

Certas estruturas, por viveram muito tempo, tornam-se elementos estáveis de uma infinidade de gerações: atravancam a história, incomodam-na, portanto, comandam-lhe o escoamento. Outras estão mais prontas a se esfacelar. Mas todas são ao mesmo tempo sustentáculos e obstáculos. Obstáculos, assinalam-se como limites dos quais o homem e suas experiências não podem libertar-se. [...] O exemplo mais acessível parece ainda o da coerção geográfica. Durante séculos, o homem é prisioneiro de climas, de vegetações, de populações animais, de culturas, de um equilíbrio lentamente construído, do qual não se pode desviar sem o risco de pôr tudo novamente em jogo (Braudel, 1969, pp. 49-50).

A preocupação do historiador com a ideia de coerção geográfica está de algum modo ligada ao seu conceito de longa duração, de forma que ambas as dimensões, espaço e tempo, sejam dilatadas a fim de se tentar depreender perenidades e ponderosidades associadas aos objetos em investigação, o que permitiria ressignificá-los e, mesmo, identificar novos problemas.

Sob influência da proposição braudelina relativa à coerção geográfica e de acordo com os interesses deste trabalho, assume-se o princípio de que o espaço físico se constitui numa dimensão da vida, presente em todo fenômeno social, uma vez que as experiências humanas, suas vivências, ocorrem necessariamente a partir de algum espaço concreto. Não há agrupamento social em qualquer momento da história que tenha se desenvolvido fora de um espaço acessível, e cujos movimentos não tenham sofrido influência do meio físico de onde se encontravam.

Um segundo aspecto importante da geografia braudeliana, muito comum a autores geopolíticos, diz respeito ao tipo de reflexão geográfica implícita em seus trabalhos. Como disse o geógrafo Yves Lacoste, seria um erro reduzir a análise do historiador francês a uma geografia de molduras estáticas, escrava da história, “[...] essa geografia imóvel de que o historiador se serve para evocar os 'tempos longos"” (Lacoste, 1988, p. 176). Em suas principais obras, Braudel desenvolveu aquilo que

\footnotetext{
${ }^{2}$ Ver Braudel (1969).

${ }^{3}$ Ver sobretudo o livro O Mediterrâneo e o Mundo Mediterrâneo na Época de Felipe II de 1949.
} 
alguns geógrafos definem como geografia fundamental, "uma geografia da ação, do movimento, uma geografia das relações de força e daquilo que se arrisca nas lutas territoriais [...].” (Lacoste, 1988: 176).

Trata-se de uma concepção ampla e, mesmo, complexa (porque contraditória) do exercício de reflexão geográfica, em que a dimensão física das configurações espaciais aparece não apenas como uma moldura rígida ou um elemento coercitivo da história humana, mas também como uma estrutura cujos significados sofrem modificações quando analisada a partir dos movimentos humanos.

Em outras palavras, as configurações espaciais podem ser pensadas a partir de seus elementos físicos e também humanos. Nesse caso, a geografia torna-se impregnada por fenômenos sociais com capacidade de alterar os entendimentos sobre seus recortes físicos, sem deixar de ser "impregnadora” de elementos coercitivos. Evita-se, com efeito, uma análise do espaço geográfico restrita às características físicas do meio, incorporando a estas elementos relativos às ações do humano, de modo que, no limite, realiza-se uma ressignificação dos próprios aspectos físicos do espaço.

Um exemplo dessa forma de reflexão geográfica pode ser encontrado na interpretação do autor sobre a derrota da Inglaterra na Guerra de Cem Anos, quando na expressão do historiador "esta se tornou uma Ilha". ${ }^{4} \mathrm{Ou}$ seja, a insularidade, um elemento constitutivo e imóvel a todas as ilhas, só adquiriu seu sentido geográfico estrito quando a Inglaterra foi expulsa do continente europeu no ano de 1453, por conta de uma derrota militar. Antes de sua expulsão, a percepção era distinta. A insularidade da Ilha não continha o mesmo significado quando pensada a partir dos movimentos dos povos que a ocupavam. O que mudou a partir daquele ano foram as dinâmicas sociais características das relações entre ingleses e os outros povos do Continente.

Há, portanto, uma harmonização de elementos dissonantes: a estrutura rígida (o espaço físico) adquire movimento por meio da análise de dinâmicas sociais que ocorrem sobre esta e sob sua influência. Esta é uma contribuição importante para os estudos que partem das configurações espaciais para pensar o sistema internacional dentro de um olhar que se pretende dinâmico, isto é, marcado por movimentos e tensões decorrentes das relações competitivas entre as unidades político-territoriais que compõem o sistema internacional.

Se os trabalhos de Fernand Braudel ajudam a pensar a respeito de uma espécie de imperativo espacial, associado a um raciocínio geográfico dinâmico (geografia fundamental), são as pesquisas de Jean Gottmann que contribuem para se refletir sobre a transformação dos espaços concretos em territórios. Para ele, a dificuldade de se tratar desse conceito decorre do entendimento do que efetivamente consiste

\footnotetext{
4 “Entre 1453 e 1558, [...] a Inglaterra, sem ter consciência disso na época, tornou-se uma ilha (perdoem-me a expressão), isto é, um espaço autônomo, distinto do continente. Até esse período decisivo, a despeito da Mancha, a despeito do mar do Norte, a despeito do estreito de Calais, a Inglaterra estava corporalmente ligada à França, aos Países Baixos, à Europa” (Braudel, 1986, p. 326)
} 
um território. Isto porque em geral se supõe que seja um "atributo por si só evidente das instituições governamentais estabelecidas" (Gottmann, 1975, p. 524).

Para o autor, isto não resolve. Propôs, assim, a noção de que território é uma porção do espaço concreto, acessível às atividades do homem e por ele delimitado, repartido, contínuo e diversificado, cuja organização, uso e exploração, inclusive econômica, dão-se necessariamente por regulares intervenções políticas.

Território é um conceito político e geográfico, porque o espaço geográfico é tanto compartimento quanto organizado através de processos políticos. Uma teoria política que ignora as características e a diferenciação do espaço geográfico opera no vácuo (Gottmann, 1975, p. 526).

Existe, portanto, uma dimensão de natureza arbitrária, não espontânea, tampouco natural, ao se recortar de alguma forma um espaço e estabelecer ali um modo específico de vida para determinado agrupamento social.

De acordo com os interesses deste trabalho, observam-se alguns aspectos daí decorrentes. Em primeiro lugar, a forma como Gottmann definiu seu conceito de território tornou-o flexível o suficiente para sua utilização em diferentes tempos históricos, uma vez que o condicionou aos espaços acessíveis ao homem. Como essa acessibilidade muda, em geral se amplia por conta do desenvolvimento técnico, os espaços passíveis de intervenção regular tendem a aumentar com o tempo. De tal modo, não fazia sentido falar, por exemplo, de espaço aéreo nacional antes da Primeira Guerra Mundial. Porém, com o advento dos aviões e seu desenvolvimento para uso militar, este espaço se incorporou ao conceito de território dos estados nacionais característicos do século XX.

Em segundo lugar, o conceito sugere implicitamente a precedência lógica da dimensão política em relação à vida econômica dentro de um território. Isto porque não há atividade econômica que ocorra à revelia de um espaço geográfico organizado; sejam as atividades de produção, cuja localização se dá em algum espaço; sejam as atividades de comércio, cujo deslocamento de produtos e serviço envolvem rotas, passagens e fronteiras; e, por fim, sejam as atividades monetário-financeiras, cujas instituições e mercados precisam se localizar em algum espaço, e cujas operações dependem de alguma moeda de conta criada por uma autoridade central estabelecida territorialmente, como será visto adiante. Assim, se toda atividade econômica estabelece uma relação com o espaço físico, este requer primeiro a intervenção política regular para seu uso e ocupação.

Sobre este segundo ponto, cabe uma observação importante. Apesar de tratar de outras questões e abordar outros temas relacionados à economia e seu lugar na sociedade, Karl Polanyi realizara um movimento metodológico semelhante ao em proposição neste trabalho: partiu do espaço concreto em que vive o homem para desenvolver sua crítica ao tratamento convencional da economia formal com base no conceito de economia substantiva por ele desenvolvido. Para o autor, ao centro do problema relativo à subsistência do homem está a ideia de que as sociedades não podem existir sem um meio físico que as sustente, em razão da própria depen- 
dência do homem à natureza, sendo a função da economia substantiva o suprimento de recursos materiais para a sociedade em geral. Ao partir disso, o autor analisou algumas formas de interação institucionalizada do homem com o meio natural em diferentes sociedades (tribais, arcaicas e modernas).

Toda tentativa de esclarecer o lugar que a economia ocupa na sociedade deve partir do fato de que o termo econômico, tal como habitualmente usado para descrever um tipo de atividade humana, contém dois significados, com raízes distintas e independentes uma da outra. Não é difícil identificá-las. O primeiro significado, o formal, provém do caráter lógico da relação meios-fins, como em economizar ou conseguir algo a baixo preço; desse significado provém a definição de econômico pela escassez. O segundo, o significado substantivo, aponta para a realidade elementar de que os seres humanos, como quaisquer outros seres vivos, não podem existir sem um meio físico que os sustente; eis a origem da definição substantiva de econômico. Os dois significados, o formal e o substantivo, nada têm em comum (Polanyi, 2012, p. 63).

Desse modo, para repensar a economia e reinseri-la na sociedade, Polanyi pôs ao centro de sua reflexão o meio físico (o espaço concreto), o que o permitiu pensar sobre a subsistência do homem a partir de lentes mais interdisciplinares, quando comparada com a da ciência econômica tradicional, sem cometer as mesmas simplificações comuns a esta. ${ }^{5}$

Há ainda um terceiro aspecto decorrente do conceito de território de Jean Gottmann. Este se perguntou sobre quais seriam os motivos que levaram à constituição e desenvolvimento de territórios. Considerou, por um lado, as necessidades de defesa de um agrupamento social em face das ameaças externas e, por outro lado, o aproveitamento de oportunidades econômicas para provimento de recursos materiais e humanos.

O território enquanto quadro para um sistema político separado é geralmente desejado para prover segurança física contra invasão ou controle estrangeiro, e como uma plataforma para a oportunidade econômica de desenvolver recursos em seu interior e em possíveis redes externas. (Gottmann, 1975, p. 529).

No entanto, o que o autor deixou de explorar foi o fato de que, se (i) ameaça externa é a razão principal para criação de territórios e se (ii) atualmente a geografia

\footnotetext{
${ }^{5}$ Sobre tais simplificações apontou como erro principal o que chamou de falácia economicista. "Reduzir o âmbito do econômico especificamente aos fenômenos de mercado é eliminar a maior parte da história humana. Em contrapartida, ampliar o conceito de mercado para fazê-lo abarcar todos os fenômenos econômicos é atribuir a todas as questões econômicas as características peculiares que acompanham um fenômeno específico (Polanyi, 2012, p. 48).
} 
política do sistema internacional caracteriza-se pela contiguidade entre as unidades político-territoriais sobre praticamente toda a extensão do planeta, poderia deduzir a partir daí a força e a centralidade que o estado permanente de tensão e preparação contra ameaças externas detém sobre a dinâmica do sistema internacional.

Esta foi uma das questões analisadas por José Luís Fiori em seu livro História, Estratégia e Desenvolvimento, quando interpretou a guerra como a principal força dinâmica e mais importante princípio hierarquizador do sistema internacional. Para tanto, o autor partiu de "[...] uma teoria do poder e da acumulação de poder [...]" (Fiori, 2014, p. 16) de um ponto de vista abstrato e conceitual para, em seguida, refletir sobre a história humana e, principalmente, a respeito do sistema interestatal capitalista de acordo com sua definição, quando analisou as relações do poder com o capital e a acumulação de capital.

É interessante notar que a transposição do nível de reflexão teórico-abstrata (sobre poder) para o âmbito das experiências humanas deu-se por meio da dimensão do espaço, mais precisamente pela ideia de território. Em suas palavras,

Na história humana, a sedentarização do poder e das relações de poder entre os homens criou territórios e fronteiras mais estáveis que os das tribos ou povos nômades. Nesses casos de sedentarização, a pressão competitiva intrínseca ao poder adquiriu maior organizidade e intensidade uma vez que já não estavam mais disponíveis as rotas de fuga do nomadismo (Fiori, 2014, p. 20).

Apesar de partirem de caminhos distintos e desenvolveram diferentes argumentos, Jean Gottmann e José Luís Fiori colocaram ao centro da noção de território o problema da guerra, da pressão competitiva e da ameaça externa. Gottmann apenas sugeriu como elemento para explicar suas origens; Fiori, ao contrário, desenvolveu uma teoria do poder da qual partiu para refletir sobre as leis de movimento de longa duração do sistema internacional e, por esta razão, percebeu desde logo o sentido estratégico inerente às reflexões geográficas, como será visto as seguir.

\section{DA GEOPOLÍTICA À GEOECONOMIA}

Em seu mais famoso livro, O Príncipe, Nicolau Maquiavel partiu do problema da conquista como critério para organizar os principados (autoridades centrais) de seu tempo e, com efeito, refletiu acerca de suas capacidades e vulnerabilidades em face das ameaças externas. O ponto central é que, para o pensador florentino, dadas as diferenças entre principados do ponto de vista de sua organização política e militar, de suas especificidades geográfica e populacional, de seu potencial econômico, etc., não seria possível haver proporcionalidade entre eles, não existindo, com efeito, harmonia razoável que garantisse a paz. Maquiavel assumiu, portanto, a questão da guerra como uma "verdade efetiva" da vida. "Não se elimina a guerra, nem se escapa dela, se adia para a vantagem de outros" (Maquiavel, 1512, p. 58). 
Trata-se de um tema com o qual as autoridades centrais deveriam se preocupar continuamente, sob pena de, em suas palavras, devastação ou servidão.

Um príncipe deve, portanto, ter como único objetivo, único pensamento e única preocupação a guerra e sua regulamentação e disciplina, [...]. [e isto porque] Nenhuma proporção existe entre alguém armado e alguém desarmado; e não é razoável que quem esteja armado obedeça de bom grado a quem esteja desarmado e que aquele que não disponha de armas possa viver em segurança entre servidores armados, pois existindo em um desdém e no outro suspeita, qualquer convivência harmoniosa entre eles é impossível (Maquiavel, 1512, p. 112).

Com efeito, quando cada unidade político-territorial se constitui numa ameaça em potencial às demais, a perspectiva de confronto torna-se um resultado crônico do sistema, marcado por uma perene pressão competitiva de uns em relação aos outros. Este seria, portanto, o desafio com o qual as autoridades são obrigadas a lidar.

No entanto, a forma como esse dilema se apresenta num determinado momento para cada uma delas não é a mesma, embora todas respondam ao mesmo problema. E uma das razões para isso é geográfica, já que cada autoridade está assentada num território único, com base em uma específica posição relativa. Ademais, se este é um problema que se repõe continuamente, tais desafios se manifestam ao longo do tempo de diferentes formas a uma mesma autoridade. Isto ocorre tanto por conta da própria dinâmica das disputas quanto por causa das transformações por que passam as sociedades em geral.

Portanto, o importante a se observar é que, embora haja um desafio que se imponha a todas as unidades do sistema internacional, as respostas a ele, provenientes de cada uma das autoridades centrais, em termos de ações conscientes e planejadas (estratégicas), são evidentemente distintas, seja quando se compara uma com as outras num mesmo momento, ou quando se analisa as ações de uma única autoridade ao longo do tempo.

Entre as autoridades centrais, além de diferentes, as estratégias são antagônicas, já que envolvem um mesmo tabuleiro geográfico percebido a partir de distintas posições relativas e com uma dinâmica marcada por uma pressão competitiva de uns em relação aos outros. Inserções e percepções diversas geram diferentes estratégias; muitas vezes, não convergentes; em outras, opostas. Porque tal disputa é dinâmica, as estratégias de uma mesma autoridade central tendem a sofrer adequações e reestruturações contínuas. Ao final e ao cabo, o que se tem é uma permanente necessidade de reflexão geoestratégica.

Foi com base nesse entendimento que Maquiavel desenvolveu seu conceito de virtù, isto é: diante dos desafios dinâmicos com os quais se deparam as autoridades centrais, sejam os relacionados às invasões, ameaças externas, sejam as conspirações contra a ordem interna, ou uma combinação de ambos, tudo o que direta ou indiretamente tem relevância ao enfrentamento dessa situação ganha conotação estratégica enquanto saber, conhecimento e arte ao príncipe. 
Dessa forma, o saber geográfico, como também todos os demais campos do conhecimento com importância ao problema da guerra, são incorporados ao exercício e à reflexão permanente do príncipe, visando à preservação e à expansão de seu poder. Foi nesse contexto que Maquiavel abordou a geografia, no sentido de uma geografia fundamental, de uma geografia da ação ou, mesmo, de uma "geopolítica", como parte constitutiva da virtù de um príncipe, diante de sua fortuna, dada, dentre outros aspectos, pelos fatos geográficos, no caso, a geografia imóvel, a geografia física.

Quanto às ações, além de manter seus homens bem disciplinados e exercitados, será conveniente praticar regularmente a caça, deste modo acostumando o corpo às durezas... e aprender a conhecer a natureza dos lugares... e descobrir como se elevam os montes, como irrompem os vales, como se estendem as planícies e compreender a natureza dos rios e dos pântanos, devotando a isto grande cuidado. Tal conhecimentos é útil de dois modos: primeiramente aprende-se a conhecer o próprio país, podendo melhor avaliar suas defesas naturais; em segundo lugar, por intermédio do conhecimento e prática nesses locais será possível compreender facilmente a situação de qualquer outro lugar que lhe seja necessário considerar, pois as colinas, os vales, as planícies, os rios, os pântanos que, por exemplo, existem na Toscana guardam certa semelhança com aqueles que existem em outras províncias, de maneira que do conhecimento dos locais de uma província pode-se facilmente chegar ao conhecimento dos de outra (Maquiavel, 1512, pp. 113-114).

Portanto, o saber geográfico adquire caráter estratégico, transformando-se num exercício contínuo e necessário (num imperativo de natureza geopolítica) às autoridades centrais que comandam as unidades político-territoriais que compõem o siste$\mathrm{ma}$ internacional. $\mathrm{O}$ conhecimento dos mais diversos aspectos que caracterizam o espaço geográfico é imprescindível à prática militar. Disto falou Yves Lacoste:

A geografia é, de início, um saber estratégico estreitamente ligado a um conjunto de práticas políticas e militares e são tais práticas que exigem um conjunto articulado de informações extremamente variadas, heteróclitas à primeira vista [...]. A geografia [...] deve absolutamente ser recolocada, como prática e como poder, no quadro das funções que exerce o aparelho de Estado, para o controle e a organização dos homens que povoam seu território e para a guerra. (Lacoste, 1985, p. 23).

Cabe observar, também, que, num sistema internacional cuja geografia política é marcada pela contiguidade, como descrito antes, tende a haver um aumento da pressão competitiva e, também, a formação de antagonismos geoestratégicos de difícil conciliação.

$\mathrm{Na}$ passagem abaixo, Robert Kaplan sintetizou algumas das ideias principais. 
[...] a geografia é o próprio fundamento da estratégia e da geopolítica. Estratégia, tal como definida por Napoleão, é a arte de fazer uso militar e diplomático do tempo e do espaço. A geopolítica consiste no estudo do ambiente externo com que cada estado se depara ao traçar sua própria estratégia - o ambiente que envolve a presença de outros Estados, também lutando pela sobrevivência e por vantagens. (Kaplan, 2012, p. 62).

Diante de tais desafios (geopolíticos), o próprio Maquiavel havia percebido um outro problema de natureza distinta: a capacidade de defesa e conquista depende do provimento regular de recursos materiais e humanos ligados direta ou indiretamente ao exercício do poder, ou através do acúmulo regular dos meios para sua aquisição (riqueza). Sem um destes, não é possível sustentar ou mesmo iniciar um conflito, como também garantir a defesa de um território. Para o autor, “[...] a meu ver podem sustentar-se por si sós aqueles que estão em condições, pela grande quantidade de homens e de dinheiro, de reunir exército adequado e combater quem quer que os venha atacar" (Maquiavel, 1512, p. 94). Em outra passagem, fez referência direta à necessidade de se assegurar, diante das ameaças externas, o provimento regular de "munições e víveres" (Maquiavel, 1512, p. 96).

Não por outra razão ou coincidência que, nos tempos de Maquiavel, esboçaram-se as primeiras formas de mercantilismo, entendido aqui como o conjunto de políticas de natureza estratégica voltadas ao aumento dos recursos materiais e da riqueza de uma autoridade central em face ao problema da ameaça externa.

O mercantilismo exprime, em todos os países, uma dupla vontade de poder, busca de grandeza e de riqueza. Na Europa Moderna, não há mais lugar de honra para os Estados incapazes de mobilizar exércitos e frotas numerosas. Não há mais lugar para os príncipes de vintém, e para os Estados ascéticos. É a prosperidade do reino que permite ao Erário alimentar o Tesouro real; é a prosperidade comercial que faz circular as espécies preciosas, medidas e condições de todo poder. O imposto é pago em moedas de ouro e de prata, porque assim são pagos os soldados, as munições, os espiões e os aliados. "É impossível fazer a guerra sem homens, manter homens sem soldo, fornecer-lhes o soldo sem tributos, arrecadar tributos sem comércio" escreveu Montchrétien (Deyon, 1969, p. 51).

Interpretar os mercantilistas fora de um contexto sistêmico e competitivo do ponto de vista da guerra é um erro muito comum nos manuais de economia em geral, pois estes organizam em abstrato o debate sobre a natureza da riqueza e as formas de expandi-la, sem qualquer referência geográfica, muito menos territorial e/ou "geopolítica".

Porém, para uma perspectiva da economia enquanto saber (geo)estratégico em relação ao problema da guerra, o segredo da expansão acelerada de riqueza está em dominar, por meio dos mais diversos instrumentos de poder, as zonas de acumulação acelerada de riqueza, vetar ali a participação de seus rivais, desenvolver 
internamente forças produtivas próprias e buscar mitigar as vulnerabilidades ligadas às garantias de acesso e abastecimento de recursos e mercados em geral.

Assim como os mercantilistas em geral, alguns autores ${ }^{6}$ identificam que o decisivo está na capacidade de estabelecer posições privilegiadas, bloqueando a concorrência ou, em termos braudelianos, erigindo contramercados. Nada mais lógico para um sistema internacional marcado pela guerra e pela competição entre as unidades político-territoriais. Ademais, não é difícil perceber que a edificação de posições privilegiadas subtende capacidade de arbítrio, ou seja, um ato de vontade, um exercício de poder, que as constrói, defende e expande.

Rudolph Hilferding, teórico do imperialismo do início do século XX, apresentou uma importante contribuição. Ao refletir sobre acumulação acelerada de capital, raciocinou com base em uma noção territorial. Percebeu que as disputas intercapitalistas não ocorriam por meio do mercado, mas pela superação da livre concorrência. E o estratégico era a construção espaços geográficos monopolizados e o mais amplo possível (territórios econômicos). Maiores territórios econômicos permitiriam ganhos em termos de complementaridade e eficiência, por conta do aumento da escala de produção, do maior controle sobre fontes de matéria-primas, acesso mais fácil aos centros consumidores e aos recursos naturais, aprofundamento da divisão do trabalho nas indústrias e na economia. Percebeu que territórios econômicos são construções derivadas das intervenções políticas regulares, do exercício de poder. Por isto que "Quanto maior o território econômico e maior o poder estatal, tanto mais privilegiada a posição do capital nacional no mercado internacional" (Hilferding, 1910, p. 311).

Se Hilferding conseguiu revelar, por meio da articulação das categorias analíticas de poder e território, a lógica de expansão dos capitais em geral e o segredo de sua capacidade de acumulação acelerada de riqueza, não o fez a partir das questões de poder associadas à dimensão geopolítica e a um sistema marcado pela perspectiva de guerra, como discutido anteriormente.

José Luís Fiori ${ }^{7}$ avançou nesse sentido ao reinterpretar a articulação entre ambas as necessidades de acumulação de poder e riqueza. Propôs uma perspectiva analítica sobre as leis de movimento de longa duração do sistema internacional, que incorporou as dimensões do poder e da riqueza de um ponto de vista dinâmico. Inverteu o raciocínio e atribuiu à guerra a origem da necessidade de acumulação de riqueza, contrapondo a ideia de acumulação de riqueza à revelia da lógica de acumulação de poder. Em suas palavras,

[...] as guerras acabaram se transformando numa espécie de "primeiro motor", e num instrumento de poder decisivo para a multiplicação das terras e dos homens capazes de criar os novos recursos que viriam a financiar novas guerras, feitas com o objetivo de gerar mais recursos, e

\footnotetext{
${ }^{6}$ Braudel (1986), Hilferding (1910) e Fiori (2014).

${ }^{7}$ Fiori (2014).
} 
assim sucessivamente [...] (Fiori, 2014, p. 21) [mais adianta completa o argumento] Sem o impulso do poder, a economia de mercado tende a se descentralizar e fragmentar, e, no limite, a se desmonetizar [...]. Com a acumulação progressiva do capital, o capitalismo adquiriu complexidade e autonomia crescentes, mas, apesar disso, teve mantida sua dependência - em última instância - em relação ao poder, mesmo após a "acumulação originária” sobre a qual fala Marx (Fiori, 2014, p. 25).

As ideias principais subjacentes aos conceitos de território de Gottmann e território econômico de Hilferding ajudam a entender o porquê dessa dependência contínua da lógica de acumulação de riqueza em relação ao poder. Como visto, não há atividade econômica que ocorra à revelia de um espaço geográfico organizado por processos políticos regulares, assim como não há acumulação acelerada de riqueza sem a construção de posições privilegiadas territoriais por meio de ações do poder.

O pensamento econômico torna-se, assim, impregnado de raciocínio geográfico e estratégico. Embora os desafios em si sejam os mesmos para diversas das autoridades centrais, suas iniciativas geoeconômicas são em geral distintas. Isto se deve, dentre outras razões, por causa da geografia e das características territoriais próprias de cada unidade política e de seus respectivos territórios econômicos. Nesse sentido, as geoestratégias devem levar em conta essas caraterísticas territoriais de modo a lidar com os desafios relativos à, por exemplo, segurança energética e alimentar, garantia de acesso aos recursos naturais estratégicos, etc.

Por fim, nota-se que o tipo de inserção econômica de uma unidade político-territorial no sistema internacional, combinado a análise dos condicionantes econômicos internos, constituem elementos importantes para se refletir acerca das estratégias econômicas voltadas à transformação das forças produtivas e militares. Algo desenvolvido, por exemplo, pela escola do pensamento cepalino. Contudo, esta não incorporou em suas análises as disputas de poder e as questões geopolíticas características do sistema internacional, uma espécie de ângulo cego, de forma que o sentido estratégico próprio ao pensamento cepalino não aborda a geografia e a guerra.

\section{VIRTÙ GEOMONETÁRIA}

Se de fato é correto pensar a partir de um imperativo geopolítico, o esforço regular de preparação para a guerra requer a organização de um sistema tributário de pagamentos monetários, que viabilize a ocupação, organização, estruturação e exploração de um espaço geográfico, sobretudo para tornar possível a extorsão dos recursos (material e humano), a alavancagem da capacidade de financiamento e gasto da autoridade central e, também, o desenvolvimento econômico associado ao esforço de guerra.

Seja qual for, a tributação é, por definição, um instrumento de poder, um ato de força. Se a guerra impunha necessidade de captação de 
enormes volumes de recursos na forma de bens e serviços, as autoridades que iniciaram, primeiramente, esse processo de monetização dos tributos foram afortunadas, pois alavancaram significativamente sua capacidade de gasto e, com efeito, suas chances de sucesso (Metri, 2014, p. 134).

Por sua vez, a moeda nada mais é do que a contrapartida da tributação, ou seja, o instrumento utilizado pela autoridade central para realizar seus gastos e aceito por ela para liquidação de dívidas tributárias, como definido em Knapp (1905). A capacidade de declarar (impor) a condição de devedor (de tributo) à coletividade sobre a qual exerce dominação é o que garante à autoridade central o privilégio exclusivo de anunciar como tais obrigações devem ser liquidadas. Apenas a autoridade central, cuja legitimidade dentro de um espaço geográfico assenta-se no domínio dos mecanismos de violência, tem a faculdade de criar uma moeda de conta, definir o meio de troca e garantir o reconhecimento social de ambos ${ }^{8}$. Com efeito, toda unidade monetária é uma denominação arbitrária. Depende de um poder que a escreva e a proclame (Knapp, 1905).

Algumas das vantagens em se monetizar a vida econômica dentro de um território são: como contrapartida da tributação, a moeda torna mais eficiente o processo de extorsão dos recursos materiais e humanos; alavanca a capacidade de financiamento e gasto da autoridade central; dá o elemento integrador das mais diferentes atividades econômicas, a moeda de conta; permite o aprofundamento da divisão do trabalho interna e, com efeito, ganhos de produtividade em escala bastante significativa quando comparada a contextos em que não há moeda.

De acordo com os propósitos deste trabalho, é importante notar que se trata de um conceito de moeda associado diretamente à dimensão do poder, por um lado, e com referência geográfica e territorial, por outro. Isto porque os limites territoriais de validade e circulação de uma moeda estão ligados diretamente ao alcance dos mecanismos de tributação ou, mais adequadamente, ao espaço de efetivo exercício da violência da autoridade central. Pode-se falar, então, de território monetário derivado de processos sociais relacionados ao fortalecimento e à expansão de uma autoridade central. De tal modo, se se supuser que essas autoridades centrais atuam a partir de desafios geopolíticos e/ou geoeconômicos, a forma que assume a organização monetária de seus territórios responderá às características desses desafios e das geoestratégias envolvidas.

Com efeito, se moeda é uma criação do poder, a internacionalização de uma determinada moeda nacional relaciona-se diretamente à capacidade de projeção internacional de sua autoridade central, de modo que a moeda de referência internacional tende a ser a da autoridade central mais bem-sucedida nas disputas geopolíticas globais. Este é um processo cujas dinâmicas se manifestam em grande medida ao final de conflitos e negociações internacionais que os acompanham. Alguns são os meios para tanto.

\footnotetext{
${ }^{8}$ Esta é a essência do conceito de moeda cartal em Knapp (1905).
} 
Em primeiro lugar, têm-se as conquistas territoriais, rotas comerciais, construções de sistemas coloniais e outras formas de expansão do espaço de dominação direta. Nesse caso, ocorre uma ampliação do alcance da tributação, assim como a possibilidade de (re)estruturação da vida econômica dos espaços tomados de modo a se instituir ali necessidades de importação e financiamento na moeda expansiva, associado muitas vezes à imposição do exclusivismo comercial metropolitano (Metri, 2014, p. 87).

Em segundo lugar, há a construção de relações econômicas hierarquizadas e assimétricas entre diferentes autoridades centrais, provenientes de negociações de acordos desiguais de natureza comercial, financeira ou de investimento, associados em geral a contextos de guerras. Em alguns casos há a definição de uma moeda específica como a de referência, cuja "escolha" reflete justamente as relações de força e poder entre as autoridades centrais envolvidas. Em outros casos, ocorre o acúmulo de desequilíbrios nas contas externas das autoridades centrais desfavorecidas nas negociações, cuja solução envolve o recurso ao endividamento na moeda expansiva (Metri, 2014, p. 88).

Por fim, pode-se falar da dominação dos espaços estratégicos e das zonas de acumulação acelerada de riqueza, característicos de cada período histórico, como, por exemplo, rotas comerciais, mercados consumidores, fontes de matérias-primas, etc. Dominados tais espaços e zonas, os demais atores tornam-se compelidos a operar com base na moeda arbitrada pelo poder expansivo, pois, do contrário, estariam deles excluídos. Dependendo da importância estratégica de tais espaços e zonas, seu domínio significa um veto às iniciativas de projeção de poder e riqueza dos demais (Metri, 2014, 89).

Em relação às vantagens de se expandir o território monetário para além do território político de origem, sublinham-se ao menos três. Por um lado, à medida que mais unidades político-territoriais passam a operar com base em uma outra moeda nacional específica em suas transações com o exterior, a autoridade central emissora desta moeda expansiva alavanca sua capacidade de financiamento e gasto, uma vez que os demais são obrigados a acumular ativos líquidos denominados na referida moeda (sobretudo papel-moeda e títulos de dívida pública) em proporção suficiente para lidar com as suas obrigações com o exterior. O próprio grau de autonomia da política cambial dos países dependerá diretamente dos seus respectivos estoques de reservas acumuladas na moeda expansiva.

Por outro lado, esses saldos acumulados tendem a ser drenados aos sistemas financeiros nacionais dos países que operam internamente com base na moeda expansiva, destaque para o sistema do país emissor da moeda internacional. Assim, quanto mais agentes operarem dentro de um território monetário específico, maior tende a ser a escala, profundidade e liquidez do sistema financeiro deste espaço nacional. Daí decorrem hierarquias e assimetrias favoráveis às instituições financeiras do país cuja moeda se impõe como a de referência internacional. Nesse sentido, não são as inovações de uma praça financeira que estimula a captação de recursos e, com efeito, o maior uso de sua moeda em transações internacionais. Ao contrário, seria a internacionalização bem-sucedida de moeda, pelos mecanismos 
acima descritos, que garante o influxo de recursos para o sistema financeiro localizado no interior do território político de origem da autoridade central cuja moeda se internacionalizou, alavancando por conseguinte sua capacidade de atuação nas atividades financeiras.

Ademais, porque toda iniciativa de transformação das forças produtivas e/ou militares nacionais acarreta o crescimento significativos da pauta e do seu volume de importações, mesmo quando seus objetivos estão voltados à substituição de importações, torna-se um imperativo a todo país, à exceção do emissor da moeda de referência, exportar produtos e serviços ou valer-se do endividamento externo (via investimento direto estrangeiro, investimento em carteira ou empréstimos e financiamentos), como estratégia para auferir a moeda internacional. Como corolário, a consolidação de uma território monetário global implica logicamente a imposição do problema da "restrição externa" aos países em geral. Com efeito, por meio do controle de importantes canais de administração da liquidez internacional, o país emissor da moeda de referência pode influenciar a capacidade de importação dos países e, portanto, suas trajetórias de desenvolvimento econômico. Em resumo, se a agenda geopolítica se impuser, a diplomacia monetária será utilizada aos propósitos da política externa, buscando restringir as oportunidades de seus inimigos estratégicos do momento e, simultaneamente, aliviar as dos aliados da ocasião. Há uma conexão direta entre geopolítica, política externa e diplomacia monetária.

Por fim, cabe observar que, por conta das significativas vantagens em se possuir a moeda de referência, as disputas monetárias internacionais adquirem importante status na competição entre as grandes potências. A projeção bem-sucedida de uma determinada moeda significa um veto a outras iniciativas semelhantes, além da imposição e da generalização do problema da restrição externa. Portanto, assim como nas lutas de poder, as disputas monetárias assumem a forma de um jogo sistêmico de posições relativas, no limite, de soma zero, onde a ascensão de um representa a queda de outros.

\section{CONCLUSÃO}

O ponto de partida da pesquisa é a ideia de que a geografia se constitui numa dimensão da vida, presente em todo fenômeno social. Por outro lado, como território é uma porção do espaço geográfico, acessível à atividade do homem, sua organização, uso e exploração se dão por processos políticos regulares. Trata-se de um imperativo territorial que se impõe à reflexão do econômico.

A interpretação de que o sistema internacional é marcado por uma pressão competitiva entre as unidades político-territoriais que o compõem, o saber geográfico adquire caráter estratégico, transformando-se numa necessidade para as autoridades centrais do sistema internacional. Nesse sentido, o conhecimento do espaço geográfico é imprescindível ao exercício e à prática militar (imperativo geopolítico). Por outro lado, diante dos desafios da guerra, a segurança implica o provimento permanente de recursos ligados ao exercício do poder, ou dos meios 
para sua aquisição, riqueza. A economia se transforma num saber estratégico também intrinsicamente relacionado ao espaço (imperativo geoeconômico). Por fim, há a necessidade de um sistema tributário-monetário que viabilize tanto a extorsão de recursos materiais como humanos situados no espaço geográfico de dominação. Nesse sentido, a internacionalização implica vantagens nada desprezíveis ao estado da moeda de referência internacional diante dos seus principais rivais dentro do sistema internacional (imperativo geomonetário).

\section{REFERÊNCIAS BIBLIOGRÁFICAS}

BRAUDEL, F. (1949[2000]). The Mediterranean and The Mediterranean World in the Age of Philip II. London: Haeper Collins Publisher Ltd..

BRAUDEL, F. (1969[2007]), Escritos sobre a História. São Paulo: Editora Perspectiva.

BRAUDEL, F. (1986[1998]), Civilização Material, Economia e Capitalismo - Séculos XV-XVIII, vol. 03, S.Paulo: Editora Martins Fontes.

DEYON, P. (1969[2004]), O Mercantilismo. São Paulo: Editora Perspectiva.

FIORI, J. L. da C., (2014) História, Estratégia e Desenvolvimento: para uma geopolítica do capitalismo. Petrópolis: Boitempo.

GOTTMANN, J. (1975[2012]) “A evolução do conceito de território”, Boletim Campineiro de Geografia, v. 2, n. 3, p. 523-545.

HELLEINER, E.; KIRSHNER, J., eds. (2009) The Future of the Dollar. Ithaca; London: Cornell University Press.

HILFERDING, R. (1910[1985]), O Capital Financeiro, São Paulo: Nova Cultura. Coleção Os Economistas.

KAPLAN, R. (2012[2013]). A Vingança da Geografia, Rio de Janeiro: Elsevier Editora Ltda..

KNAPP, G. F. (1905[2003]), The State Theory of Money, San Diego: Simon Publications.

LACOSTE, Y. (1985[20080]), A Geografia - Isso Serve, em Primeiro Lugar, para Fazer a Guerra, Campinas: Papirus Editora.

LACOSTE, Y., org. (1989) Ler Braudel, Campinas: Papirus Editora.

MAQUIAVEL, N. (1513[1973]), O Príncipe, Os Pensadores, São Paulo: Editora Civita.

METRI, M.(2014) Poder, Riqueza e Moeda na Europa Medieval, Rio de Janeiro: Editora FGV.

POLANYI, K., (2012) A Subsistência do Homem e Ensaios Correlatos, Rio de Janeiro: Contraponto. 